\title{
Dinâmica Populacional de Fitonematoides em Sistema Integrado de Produção de Milho
}

\author{
Guido Calgaro Junior ${ }^{1}$, Leonardo de Castro Santos ${ }^{2}$, Tiago do Prado Paim ${ }^{3}$, Estenio Moreira Alves ${ }^{1}$, \\ Giullia Manoela Moraes Silva ${ }^{1} \&$ Flavio Lopes Claudio ${ }^{1}$
}

Recebido em 11/08/2020 - Aceito em 14/12/2020

1 Instituto Federal de Educação, Ciência e Tecnologia Goiano/IF Goiano, Campus Iporá, Iporá/GO, Brasil. CEP: 76.200-000. <guido.junior@ifgoiano.edu.br, estenio.moreira@ifgoiano.edu.br, giulliamoraes9@gmail.com, flavio.claudio@ifgoiano.edu.br>.

2 Instituto Federal de Educação, Ciência e Tecnologia Goiano/IF Goiano, Polo de Inovação, Programa de Pós-Graduação em Bioenergia e Grãos/PPGBG, Rio Verde/GO, Brasil. CEP: 75.906-750. <leonardo.castro@ifgoiano.edu.br>.

3 Instituto Federal de Educação, Ciência e Tecnologia Goiano/IF Goiano, Campus Rio Verde, Rio Verde/GO, Brasil. CEP: 75.906-750. <tiago.paim@ifgoiano.edu.br>.

RESUMO - Os Sistemas Integrados de Produção Agropecuária vêm crescendo no Brasil como alternativa mais sustentável de produção de grãos, bem como recuperação de áreas de pastagem em degradação. No entanto, têm-se poucas informações sobre a dinâmica de nematoides nesses sistemas, os quais podem acarretar perdas de produtividade. Objetivou-se, assim, verificar a dinâmica de fitonematoides durante a implementação do sistema integrado de produção de milho. O experimento foi conduzido em Iporá - GO, avaliando-se três tratamentos (épocas de plantio do milho) durante 14 meses. A população e produção de matéria seca dos três componentes foram mensurados. Os tratamentos foram analisados por modelos mistos, efeitos fixos e aleatórios utilizados, e as médias comparadas usando o ajuste de Tukey. Para avaliar a relação entre as variáveis, foram realizadas análises de correlação e componentes principais - Principal Components Analysis (PCA). Verificouse que o aumento populacional de fitonematoides do gênero Pratylenchus e Criconemella está relacionado com as épocas do ano e com a umidade do solo, destacando-se para a temperatura mais elevada. Não se observou correlação significativa entre produção de grãos e população de fitonematoides. A população de fitonematoides não diferiu entre a área em que foi implementado o Sistema Integrado de Produção Agropecuária (SIPA) em relação à área de pastagem em degradação $e$ de mata nativa (Cerrado). A implementação do SIPA não afetou a população de fitonematoides, $e$ estes não afetaram a produção do milho.

Palavras-chave: Zea mays; nematoides fitoparasitas; guandu; capim tamani.

\section{Population Dynamics of Phytonmatoids in Integrated Corn Production System}

ABSTRACT - In Brazil, the Integrated Agricultural Production Systems, both of the search of more sustainable alternatives of grain production and in the degraded areas recovery. However, they have little information about some pests, diseases and nematodes dynamics soil systems, which can lead to productivity losses. This work aimed to verify the appropriate adjustments during the integrated production system. The experiment was carried out in Iporá - GO, evaluating three treatments (corn planting times) during 14 months of evaluation. The population and dry matter production of the three components were measured. Weather data were also collected. The treatments were analyzed by mixed models and the comparison with other areas was performed by analysis of variance. When any effect was identified, Tukey test was applied for means comparison. To assess the relationship between the variables, correlation, regression and principal component - Principal Components Analysis (PCA) analyzes were performed. It was verified that the population increase of Pratylenchus and Criconemella Plant-parasitic nematodes are related to the year time and soil moisture, highlighting the maximum temperature. The plant-parasitic nematodes population did not differ between the area in which the integrated agricultural production system (SIPA) was implanted in relation to the degrading pasture area and native forest (Cerrado). The SIPA implantation did not affect the population of plantparasitic nematodes and they did not affect the corn production.

Keywords: Zea mays L.; plant-parasitic nematodes; guandu; grass tamani. 


\title{
Dinámica Poblacional de Fitonmatoides en el Sistema Integrado de Producción de Maíz
}

\begin{abstract}
RESUMEN - Los Sistemas Integrados de Producción Agropecuaria han ido creciendo en Brasil como una alternativa más sostenible para la producción de granos y la recuperación depastizales degradados. Sin embargo, existe poca información sobre la dinámica de losnematodos en este sistema, lo que puede provocar pérdidas de productividad. Así, elobjetivo fue verificar la dinámica de los nematodos fitoparasitos durante la implementación delsistema integrado de producción de maíz. El experimento se realizó en Iporá - Goiás, Brasil, evaluando tres tratamientos (tiempos de siembra de maíz) durante 14 meses. Se midió la población y la producción de materia seca de los tres componentes. Los tratamientos se analizaron mediante modelos mixtos, se utilizaron efectos fijos y aleatorios y se compararon los promedios mediante el ajuste de Tukey. Para evaluar la relación entre las variables se realizaron análisis de correlación y de Componentes Principales - Análisis componentes principales (PCA). Se encontró que el aumento de población de los fitonemátodos de los géneros Pratylenchus y Criconemella está relacionado con las épocas del año y con la humedad del suelo, especialmente por la temperatura más alta. No hubo correlación significativa entre la producción de granos y la población de fitonematodos. La población de los nematodos fitoparasitos no difirió entre el área en la que se implantó el Sistema Integrado de Producción Agropecuaria (SIPA) en relación al área de pastos degradados y bosque nativo (Cerrado). La implantación de SIPA no afectó la población de fitonemátodos y no afectó la producción de maíz.
\end{abstract}

Palabras clave: Zea mays L.; nemátodos fitoparásitos; gandul; hierba tamani.

\section{Introdução}

Os fitonematoides são seres microscópicos que habitam o solo em diferentes áreas e locais, e que se alimentam principalmente de raízes de plantas. Nematoides fitoparasitos são seres habitantes do solo e, dependendo da dinâmica de produção e manejo das culturas, podem se tornar um problema fitossanitário, com possibilidades de limitar a produção e a utilização de áreas para plantio. Os fitonematoides provocam injúrias nos cultivos, variando a dinâmica populacional e o modo de parasitismo. Conforme o gênero da população diagnosticada, além das condições edafo-climáticas e a idade da planta, a sintomatologia pode ser severa $e$, ainda, podem tornar essa área, com essa infestação natural, imprópria para o cultivo de alguma espécie de importância econômica (Hugot et al., 2001). A fonte de inóculo primário dos fitonematoides pode ser oriunda da vegetação nativa (Inomoto, 2011).

Práticas culturais inadequadas e uso do monocultivo nas áreas agrícolas do Centro-Oeste brasileiro trouxeram o aumento significativo da degradação do solo e dos recursos naturais. A consequência desse processo foi a queda de produtividade, o aumento de pragas e doenças, prejudicando a sustentabilidade da produção agrícola (Yorinori et al., 1993). Por isso, os produtores buscam alternativas para resolver esses problemas. Assim, o Sistema Integrado de
Produção Agropecuária (SIPA) tem se expandido no Brasil, trazendo vários benefícios econômicos e ambientais (Balbino et al., 2011). Esse sistema conduz a melhorias das propriedades físicas, químicas e biológicas do solo, e a quebra de ciclos bióticos (pragas e doenças), aumentando a produtividade (Vilela et al., 2008).

No Sistema Integrado de Produção, o uso do milho em consórcio com o capim é economicamente viável e lucrativo. Para cobrir os custos da recuperação da pastagem, neste caso, o milho vem sendo uma das melhores alternativas (Cobucci et al., 2007). No entanto, essa cultura tem alta suscetibilidade aos fitonematoides do gênero Pratylenchus (Inomoto, 2011; Chiamolera et al., 2012).

O manejo de fitonematoides em SIPA deve considerar alguns fatores como a contaminação e a susceptibilidade das culturas, visto que a população poderá variar de acordo com as culturas e os manejos empregados; sendo assim, precisa estar sempre monitorando a área com relação aos fitonematoides presentes, (Inomoto, 2013); (Asmus, 2013). As informações da dinâmica populacional de fitonematoides em tais áreas são importantes para novas alternativas de manejo. Assim, o presente estudo objetivou verificar a dinâmica dos fitonematoides durante a implantação de um sistema integrado de produção de milho. 


\section{Material e Métodos}

O experimento foi conduzido na fazenda Boa Esperança, localizada nas coordenadas geográficas: $16^{\circ} 26^{\prime} 31^{\prime \prime}$ de latitude Sul, $51^{\circ} 01^{\prime} 06^{\prime \prime}$ de longitude Oeste, altitude de 488 metros. A área do experimento foi de $37.500 \mathrm{~m}^{2}$, dividida em três áreas iguais de $12.500 \mathrm{~m}^{2}$, subdividida em quatro áreas (repetições) com medidas de $3.125 \mathrm{~m}^{2}$ (Figura 1). $\mathrm{Na}$ imagem da área experimental, o contorno da linha amarela é a área total da propriedade, e o contorno de linha vermelha é a área experimental onde foram realizadas as coletas (Figura 1). De acordo com o Sistema de Meteorologia e Hidrologia do Estado de Goiás (SIMEHGO) e Agência Nacional de Águas (ANA), Iporá - $\mathrm{GO}$ tem variação média de temperatura entre $24^{\circ} \mathrm{C}$ a $25^{\circ} \mathrm{C}$ e índice pluviométrico médio de 1628mm anuais (Souza, 2017).
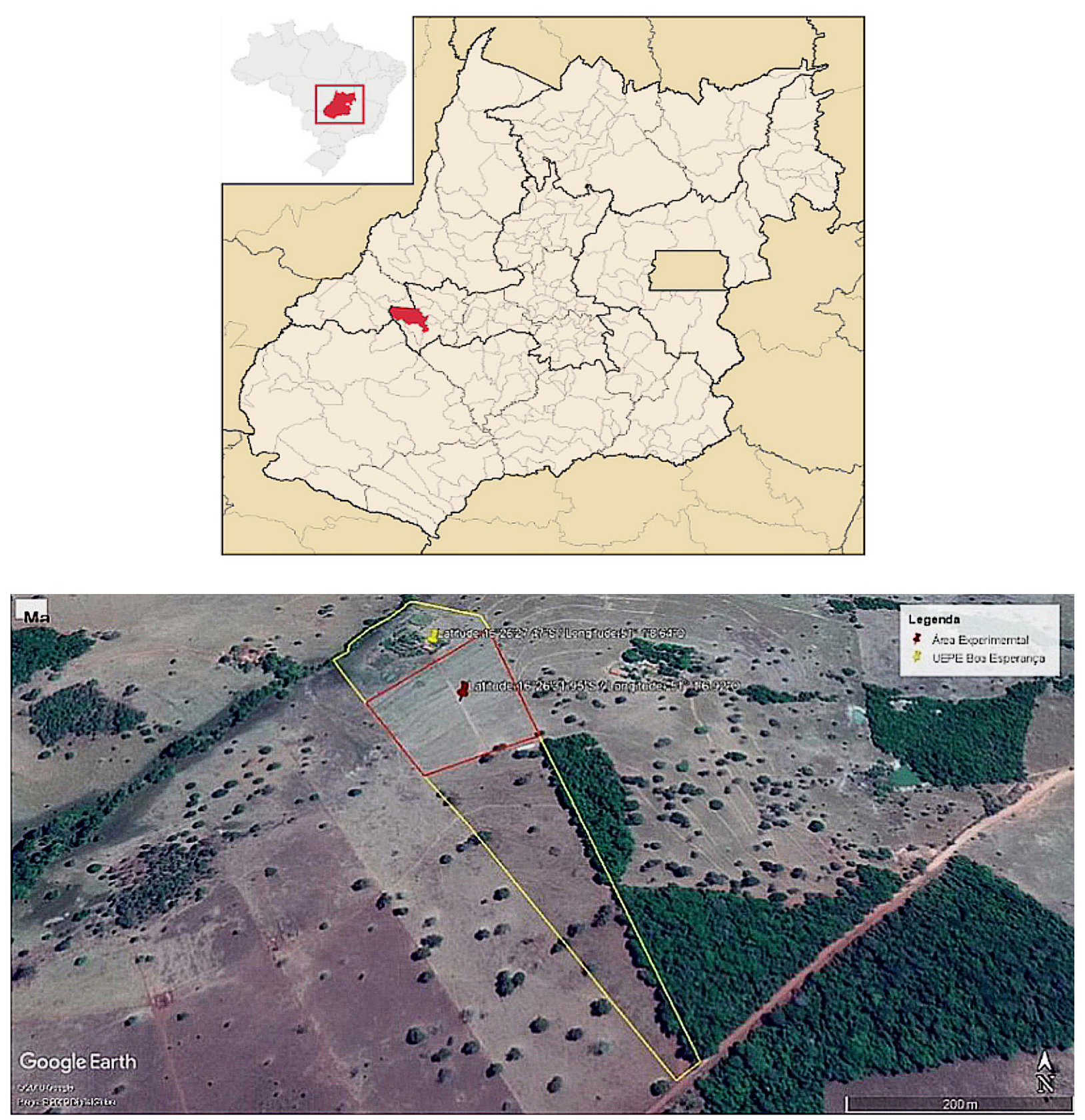

Figura 1 - Imagem do Brasil com destaque para Goiás. Imagem de Goiás com destaque para o município de Iporá (à esquerda). Fonte: Wikipédia (2019). Imagem de satélite da área experimental (à direita). Fonte: Google Earth (2018). 
$\mathrm{Na}$ área experimental, o delineamento foi inteiramente ao acaso, com três tratamentos $e$ quatro repetições. Os tratamentos foram em três diferentes épocas de implementação do cultivo de milho (09 de novembro de 2017, 29 de novembro de 2017 e 18 de dezembro de 2017). As coletas foram realizadas mensalmente entre dezembro de 2017 e janeiro de 2019.

Com o intuito de recuperar a pastagem degradada da área, utilizou-se um consórcio tríplice (milho, guandu e capim). Além de avaliar a produção de milho grão e/ou silagem. Semeou-se, ao mesmo tempo, o milho híbrido cv. 'AG1051' consorciado com feijão guandu cv. 'Super N' $e$ capim cv. 'BRS Tamani'.

A população de plantas/taxa de semeadura do tríplice consórcio foi o seguinte: $5 \mathrm{~kg} \cdot \mathrm{ha}^{-1}$ de sementes puras viáveis (SPV) de capim cv. BRS 'Tamani', 19 sementes por metro linear de guandu, seis sementes de milho por metro linear. O semeio foi realizado com cinco linhas espaçadas a $0,50 \mathrm{~m}$ entre as linhas, das quais três linhas foram de milho e duas linhas de guandu, intercaladas. As sementes do capim foram distribuídas a lanço por fluxo contínuo na terceira caixa de sementes da semeadora, cobrindo a faixa de semeio das cinco linhas na operação de semeio.

Realizou-se a calagem com 1,8ton.ha ${ }^{-1}$ de calcário e adubação com 4 ton ha $^{-1}$ de cama de frango. $\mathrm{Na}$ adubação de base aplicou-se 200kg. ha ${ }^{-1}$ do adubo formulado: 7-41-5 na base, e 200kg.ha-1 de ureia em cobertura, parcelada em duas operações nos estágios V2 e V4 do milho.

Logo após a semeadura do milho, iniciaramse as coletas das amostras para a quantificação dos fitonematoides. A coleta de solo foi realizada da seguinte forma: cinco amostras simples para compor uma amostra composta dentro da mesma parcela. A coleta de raiz nos meses de dezembro de 2017, janeiro de 2018, fevereiro de 2018 e março de 2018 foram amostras de raízes de milho; a partir do mês de abril de 2018 até janeiro de 2019 , as amostras de raiz foram de capim. Todas as amostragens para quantificação $e$ identificação dos fitonematoides foram realizadas mensalmente, iniciando-se em dezembro de 2017 e finalizando em janeiro de 2019.

Ao todo foram coletadas 332 amostras, 12 parcelas, e foram coletadas durante 14 meses, sendo 12 amostras de solo e 12 amostras de raízes. Nas coletas de solo, utilizou-se trado holandês e cavadeira. As amostras de raiz foram coletadas com enxadão. As amostras foram acondicionadas em sacolas plásticas para o transporte até o laboratório de Microbiologia e Fitopatologia do Instituto Federal Goiano - Campus Iporá, local onde foram conservadas refrigeradas, para posterior extração, análise e contagens.

Os dados obtidos referentes à população de fitonematoides foram correlacionados com dados meteorológicos e dados agronômicos de produção. Os dados meteorológicos foram coletados na estação automática denominada Iporá-A028, código OMM: 86731, aberta em 24/06/2013, com localização latitude: $-16.423059^{\circ}$, Longitude $-51,148801^{\circ}$ e com altitude de 610 metros, podendo ser observada a distribuição de chuvas bem como a variação de temperatura ao longo do período em que foram realizadas as coletas.

Para determinação dos resultados agronômicos foram feitas amostragens da biomassa em matéria seca disponível no momento da colheita da silagem. Coletaram-se quatro amostras de $2 \mathrm{~m}^{2}$ por piquete para determinar a produtividade e estratificação da biomassa. As amostras foram acondicionadas em estufa com temperatura de $65^{\circ} \mathrm{C}$ constante por 72 horas para determinação da matéria seca. O material coletado foi processado por tipo de forragem. Determinou-se a produtividade de grãos e a produção de matéria seca estratificada por espécie utilizada no tríplice consórcio e total. Ainda se determinou o estande final de milho e guandu em $2 \mathrm{~m}^{2}$.

Para estimar a produtividade de grãos de milho, adotou-se o índice de colheita de $44 \%$ proposto para o milho híbrido cv. "AG 1051, Aguiar et al. (2003), calculado a partir do volume proporcional de matéria seca da planta colhida; a planta foi coletada ainda em fase de umidade mais elevada. Essa metodologia é utilizada para a estimativa de produtividade de grãos, antecipadamente à secagem por completo do milho. Foi realizada amostragem de solo nos meses de junho de 2017, agosto de 2018 e fevereiro de 2019 para determinar o teor de matéria orgânica do solo em gramas $/ \mathrm{kg}$.

\section{Análise de nematoide}

Para a extração dos nematoides nas amostras de solo, uma alíquota de $100 \mathrm{~cm}^{3}$ foi submetida à metodologia proposta por Jenkins (1964), e cada 
amostra de solo foi homogeneizada com água, em volume de 1 litro equivalendo de oito a dez vezes ao volume de solo. Em seguida, filtrou-se o sobrenadante em duas peneiras acopladas, sendo a superior com porosidade de 20 mesh e a inferior com porosidade de 400 mesh. O conteúdo retido na peneira de 400 mesh foi lavado com água e recolhido em béquer, com auxílio de uma pisseta (Jenkins, 1964).

O conteúdo do béquer foi acondicionado em tubos e levado para centrifugação, durante 5 minutos a $1.800 \mathrm{rpm}$. Após esse processo, o sobrenadante foi descartado e adicionada solução de sacarose de densidade 1,15 , levando novamente para a centrífuga, por um minuto, a $1.800 \mathrm{rpm}$. Verteu-se o sobrenadante em peneira de malha de 400 mesh, lavando-a, em seguida, com água para eliminar resíduos da solução açucarada. Com auxílio de pisseta, recuperou-se o material retido na peneira em água e o transferiu para tubo de ensaio. O material final obtido foi examinado no microscópio estereoscópio.

As amostras de raiz foram lavadas em água corrente e cortadas em pedaços de $2 \mathrm{~cm}$ a $3 \mathrm{~cm}$, e, em seguida, trituradas em liquidificador contendo $250 \mathrm{ml}$ de água, por 30 segundos - metodologia proposta por Coolen \& D'Herde (1972). A solução produzida foi vertida em peneiras sobrepostas, de 100 mesh sobre 400 mesh. Recuperou-se o material retido na peneira 400 mesh (nematoides + resíduos vegetais), acondicionando-os em béquer. A solução recuperada foi submetida à centrifugação por 5 minutos a $1.800 \mathrm{rpm}$.

O sobrenadante foi descartado $e$, posteriormente, foi adicionada a solução de sacarose, de densidade 1,15 , ao resíduo, retornando para a centrífuga deixando funcionar por um minuto a $1.800 \mathrm{rpm}$. Após este processo, verteu-se o sobrenadante por peneira 400 mesh, lavando-a com água para eliminar resíduos da solução açucarada, com auxílio de pisseta. Recuperou-se o material retido na peneira, transferindo-o com água para tubo de ensaio. De posse da amostra, precedeu à identificação e à quantificação dos fitonematoides com auxílio de microscópio estereoscópio.

\section{Análise estatística}

Todos os dados de contagem de nematoides (raiz e solo) foram transformados a log $(\mathrm{x}+1)$ para diminuir o desvio da distribuição normal dos resíduos. Testes para determinar a presença de outliers, a homogeneidade de variâncias (Bartlett) e a distribuição normal dos resíduos (ShapiroWilk) foram realizados antes da análise estatística $e$ interpretação dos dados. As análises foram feitas com o objetivo de identificar quais gêneros de fitonematoides estavam presentes na área, bem como a sua quantificação, comparando-se a área que teve intervenção com a área sem intervenção alguma (controle).

Avaliou-se a dinâmica dessas populações existentes ao longo do tempo, nas diferentes épocas de semeadura dos consórcios, e as possíveis correlações entre todas as variáveis fitotécnicas, populações e gêneros de fitonematoides, dados meteorológicos (umidade mínima, máxima $e$ instantânea do ar, precipitação, temperatura mínima, máxima e instantânea). O efeito dos tratamentos e período de coleta (mês do ano) foram determinados por modelos mistos, considerando-se tratamento e mês de coleta como efeitos fixos, e o piquete, como efeito aleatório. Para a análise de modelos mistos utilizou-se o pacote lme4, Bates et al. (2011) do software $\mathrm{R}$ versão 2.13, $R$ Development Core Team (2011). O efeito do tratamento (diferentes épocas de plantio) sob a população de nematóides foi determinado por análise de variância usando a função aov do software Rversão 2.13, R Development Core Team (2011). Em ambos os casos, quando houve efeito de tratamento $(\mathrm{P}<0,05)$, a comparação de médias foi realizada usando teste de Tukey.

Foram realizadas análises de correlação entre a população de nematoides e produtividade, bem como entre a população de nematoides $e$ as variáveis climáticas. Para esta análise, foi utilizado o pacote Hmisc no software R. Para a análise de regressão linear entre produtividade de matéria seca total e de cada componente em relação a população de nematoides, utilizou-se a função $\mathrm{lm}$ no software R. Foi testado também o efeito da população de nematoides sobre a população final de plantas de cada componente do consórcio. Após a análise de regressão, a normalidade dos resíduos, homogeneidade da variância residual $e$ independência do erro foram avaliadas para determinar o melhor modelo. Todos os dados quantitativos (produtividade $e$ população das culturas, variáveis meteorológicas e população de nematoides) foram submetidos à análise multivariada de componentes principais. 
Para tanto, utilizaram-se os pacotes FactoMineR e factoextra do software R. Os gráficos foram gerados com o uso do pacote ggplot2 no mesmo software.

\section{Resultados}

Três gêneros de fitonematoides foram encontradosnaárea:Pratylenchus, Helicotylenchus $e$ Criconemella. Tanto em amostras de raiz quanto de solo, houve predomínio do gênero Pratylenchus.

O Helicotylenchus está sendo encontrado na grande maioria das regiões produtoras do estado de Goiás, que responde por grande parte da produção de milho em nível nacional (Mattos et al., 2006). Este fitonematoide foi encontrado em áreas de cultivo de café e tomate no estado de Goiás (Machado et al., 2019). Desta maneira, deverá ser uma espécie monitorada nos próximos anos, mesmo não apresentando danos severos, além de haver escassas referências que mostram prejuízos. Sendo assim, é necessário cuidado quanto ao seu aumento populacional. Segundo Tomazini (2008), as áreas que recebem influências de diferentes usos na agricultura têm aumento de Helicotylenchus.

As contagens dos fitonematoides de ambos os gêneros encontrados não sofreram efeito, quando relacionados com a época de semeio do milho. A interação entre a época de semeadura do milho, quando relacionado com a época de coleta, bem como com o ano de coleta, não apresentou diferença estatística (Tabela 1).

Tabela 1 - Resultados das contagens de fitonematoides $\left(\mathrm{N} / \mathrm{cm}^{3}\right)$ nas raízes, realizadas mensalmente de dezembro de 2017 a janeiro 2019 em sistema integrado de produção de milho, guandu e tamani.

\begin{tabular}{|c|c|c|c|}
\hline Raiz & Pratylenchus & Helicotylenchus & Criconemella \\
\hline Época de semeio & ns & ns & ns \\
\hline Mês.ano & $* * *$ & ns & ns \\
\hline Época de semeio*Mês.ano & ns & ns & ns \\
\hline \multicolumn{4}{|l|}{ Época de semeio } \\
\hline 09/11/17 & $2,327 \mathrm{a}$ & $0,057 \mathrm{a}$ & $0,000 \mathrm{a}$ \\
\hline $29 / 11 / 17$ & $1,627 \mathrm{a}$ & $0,011 \mathrm{a}$ & $0,000 \mathrm{a}$ \\
\hline $18 / 12 / 17$ & $1,261 \mathrm{a}$ & $0,012 \mathrm{a}$ & $0,067 \mathrm{a}$ \\
\hline \multicolumn{4}{|l|}{ Mês.ano } \\
\hline Dez 2017 & $0,856 \mathrm{c}$ & $0,000 \mathrm{a}$ & $0,000 \mathrm{a}$ \\
\hline Jan 2018 & $0,082 \mathrm{c}$ & $0,053 \mathrm{a}$ & $0,000 \mathrm{a}$ \\
\hline Fev 2018 & $0,378 \mathrm{c}$ & $0,000 \mathrm{a}$ & $0,000 \mathrm{a}$ \\
\hline Mar 2018 & $0,017 \mathrm{c}$ & $0,000 \mathrm{a}$ & $0,000 \mathrm{a}$ \\
\hline Abr 2018 & $0,384 \mathrm{c}$ & $0,264 \mathrm{a}$ & $0,000 \mathrm{a}$ \\
\hline Mai 2018 & $0,191 \mathrm{c}$ & $0,000 \mathrm{a}$ & $0,000 \mathrm{a}$ \\
\hline Jun 2018 & $0,000 \mathrm{c}$ & $0,000 \mathrm{a}$ & $0,000 \mathrm{a}$ \\
\hline Jul 2018 & $1,224 \mathrm{c}$ & $0,000 \mathrm{a}$ & $0,000 \mathrm{a}$ \\
\hline Ago 2018 & $1,855 \mathrm{c}$ & $0,000 \mathrm{a}$ & $0,000 \mathrm{a}$ \\
\hline Set 2018 & $2,505 c$ & $0,000 \mathrm{a}$ & $0,240 \mathrm{a}$ \\
\hline Out 2018 & $7,303 \mathrm{a}$ & $0,000 \mathrm{a}$ & $0,073 \mathrm{a}$ \\
\hline Nov 2018 & $2,291 \mathrm{c}$ & $0,000 \mathrm{a}$ & $0,000 \mathrm{a}$ \\
\hline Dez 2018 & $2,154 \mathrm{c}$ & $0,000 \mathrm{a}$ & $0,000 \mathrm{a}$ \\
\hline Jan 2019 & $5,095 \mathrm{~b}$ & $0,057 \mathrm{a}$ & $0,000 \mathrm{a}$ \\
\hline
\end{tabular}

Ns: não significativo $(\mathrm{P}>0,05)$; *: $\mathrm{P}<0,05 ;$ **: $\mathrm{P}<0,01$; ***: $\mathrm{P}<0,001$. Letras diferentes na mesma coluna indicam diferença significativa pelo teste de Scott Knott $(\mathrm{P}<0,05)$. 
O mês de coleta foi significativo somente para a população de Pratylenchus. Os meses de setembro e outubro de 2018 foram marcados pelo início das chuvas e elevação das temperaturas, desta forma, existe uma disponibilidade maior de alimento, o que favorece os fitonematoides, com característica de polifagia, como o nematoide das lesões radiculares. Foram meses em que se obser- vou um aumento na população de fitonematoides (McDonald \& Berg, 1993). A temperatura ideal para sua reprodução de Pratylenchus varia entre 15 e $30^{\circ} \mathrm{C}$, e seu ciclo de ovo a ovo varia de 2 a 4 semanas (Freitas et al., 2014). No mês de janeiro de 2019 observou-se um alto nível na população do gênero Pratylenchus, motivado pelo nível de umidade no solo e disponibilidade de alimentos (Figura 2).

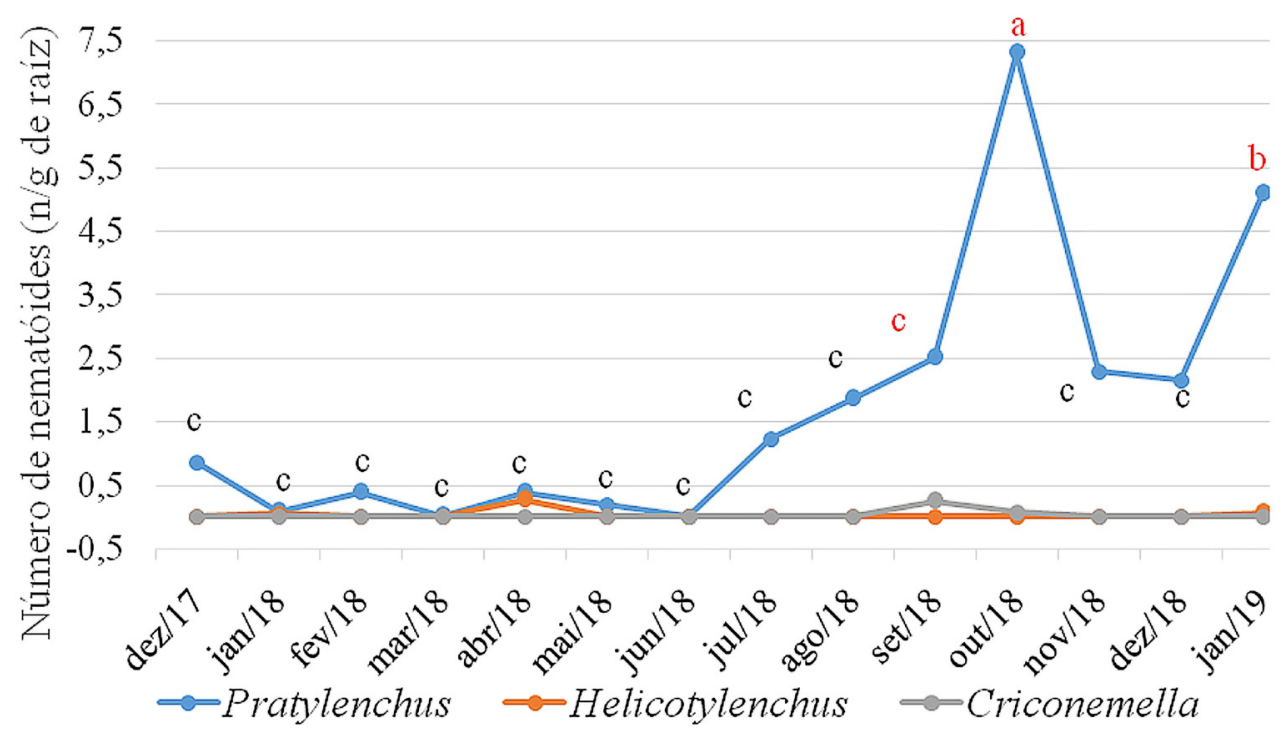

Figura 2 - População de fitonematoides encontrados nas amostras de raízes entre o período de dezembro de 2017 a janeiro de 2019. Iporá (2019).

Portanto, ao final do período da avaliação, observou-se maior população de nematóides do gênero Pratylenchus. Conhecido como nematoide das lesões radiculares, devido ao ciclo de vida $e$ relação endoparasita com o hospedeiro, o Pratylenchus tem grande capacidade de se alimentar das diferentes plantas encontradas na área, devido à característica de polifagia, típica às espécies desse gênero. Existe uma relação do aumento do nível populacional desse fitonematoide com a disponibilidade de alimento, em função da maior produção vegetal na área, impulsionada pelo consórcio (Alves et al., 2011). Pela grande diversidade de plantas que são favorecidas por boas condições edáficas e, com isso, devido ao Pratylenchus ser um parasita obrigatório, ou seja, estabelece sua relação de parasitismo com a planta viva, essas melhores condições para o desenvolvimento da planta incrementará a colonização e reprodução do nematoide, (Asmus \& Ishimi, 2009). Além da interação entre os organismos presentes no solo com este fitonematoide, que possui alto grau de polifagia (Ferraz, 2006; Alves et al., 2011; Moreira, 2012; Ferraz et al., 2014).

Pôde-se observar que o aumento dos fitonematoides está ligado diretamente com o aumento da temperatura, a disponibilidade de alimentos e a época do ano. Os meses de setembro e outubro de 2018 tiveram aumento significativo na população do nematoide (Tabela 1). Esses meses correspondem ao aumento da temperatura ambiente que teve relação significativa com a população desse nematoide (Figura 2).

Pratylenchus tem a cultura do milho como hospedeira favorável, bem como as forrageiras utilizadas no uso em consórcio em SIPA (Debiase et al., 2016). A quantidade de palha que esse consórcio deixa na área é bem expressiva, e se transformará em matéria orgânica. A matéria orgânica, resultante da degradação da palhada, 


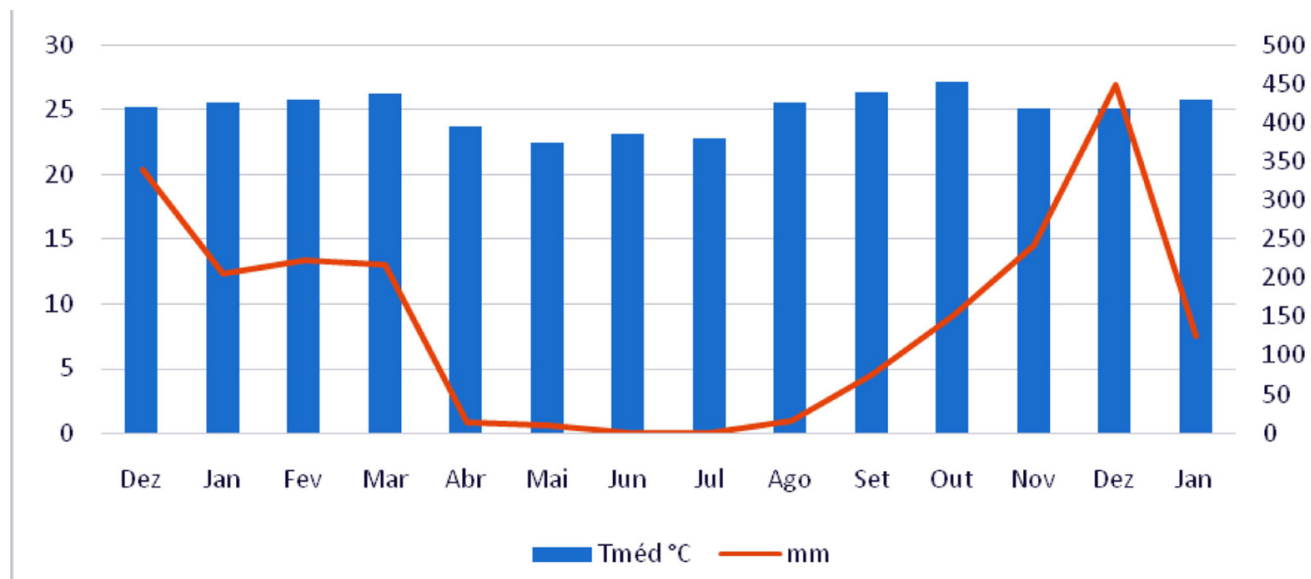

Figura 3 - Médias de temperatura e precipitação acumuladas entre dezembro de 2017 e janeiro de 2019 no município de Iporá.

pode aumentar a diversidade microbiana no solo. Dentre os micro-organismos que serão favorecidos com essa ciclagem de nutrientes, está a microbiota parasita e predadora de nematoides fitoparasitas. Desta forma, essa dinâmica microbiológica pode manter a população de fitonematoides em equilíbrio no solo (Dong et al., 2013).

Os gêneros Helicotylenchus e Criconemella não apresentaram diferença na população ao longo do tempo de avaliação. Com relação aos resultados obtidos nas contagens de nematoides no solo, observou-se que não houve efeito signifi- cativo de tratamento, mês do ano e da respectiva interação (Tabela 2) para nenhum dos gêneros de fitonematoides estudados. O Pratylenchus no solo mostrou correlação positiva com precipitação acumulada. Os meses de dezembro de 2017 e 2018 foram os períodos de maiores contagens desse fitonematoide. Esse aumento pode estar relacionado com a facilidade de deslocamento pelo filme de água devido ao seu hábito migrador, na busca por alimentos, por ser um nematoide com alto grau de ingestão de alimentos (Ferraz, 2006). (Figura 4).

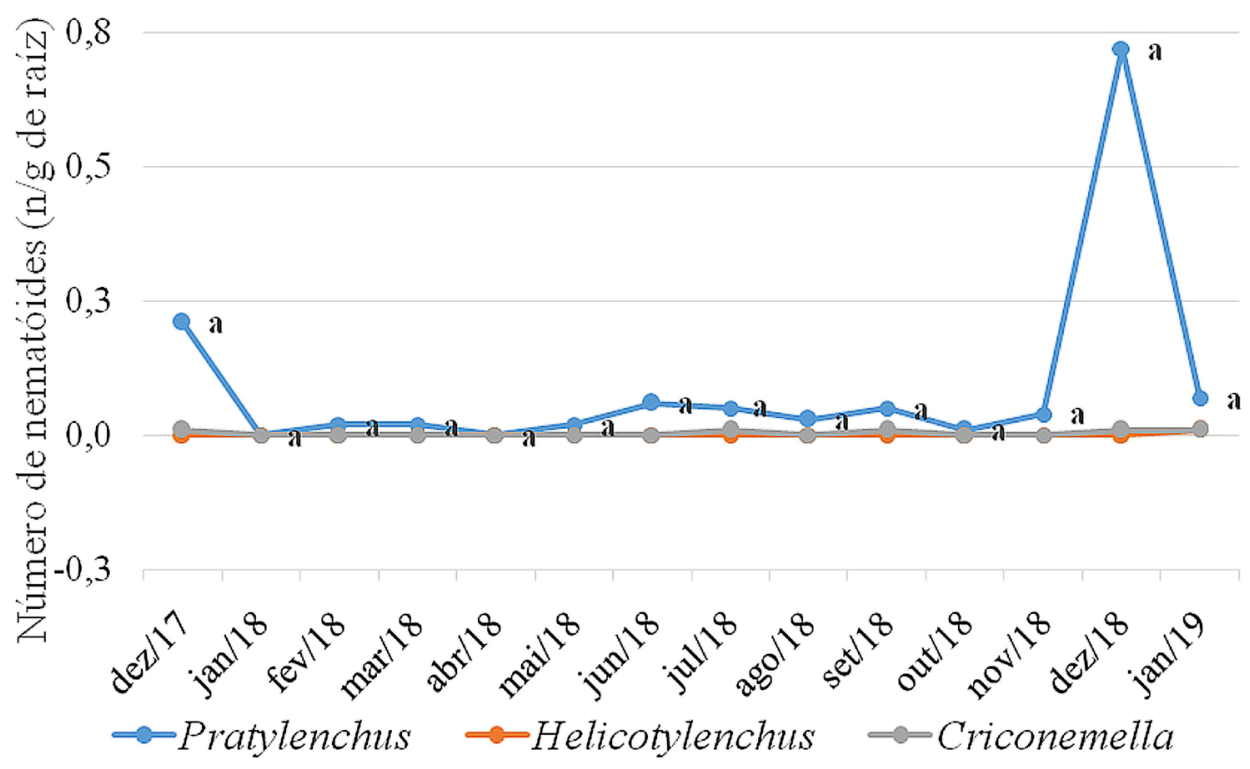

Figura 4 - Resultado dos fitonematoides encontrados nas amostras de solo coletadas entre o período de dezembro de 2017 a janeiro de 2019 no município de Iporá (2019). 
Pode-se observar que não houve uma relação significativa nos dados das amostras de solo para nenhum dos gêneros de fitonematoides encontrados, não sendo afetada a produtividade do capim nem do milho (Tabela 2). A ausência de correlação entre a população na raiz e no solo para Pratylenchus reforçou a observação de efeito do tempo sobre a população na raiz, e a não observação desse efeito sobre a população no solo (Machado et al., 2000).

Tabela 2 - Resultados das contagens de fitonematoides no solo realizadas mensalmente de dezembro de 2017 a janeiro 2019 em sistema integrado de produção de milho, guandu e tamani, no município de Iporá (2019).

\begin{tabular}{|c|c|c|c|}
\hline Solo & Pratylenchus & Helicotylenchus & Criconemella \\
\hline Época de semeio & ns & ns & ns \\
\hline Mês.ano & ns & ns & ns \\
\hline Tratamento*Mês.ano & ns & ns & ns \\
\hline \multicolumn{4}{|l|}{ Época de semeio } \\
\hline 09/11/17 & $0,053 \mathrm{a}$ & $0,002 \mathrm{a}$ & $0,005 \mathrm{a}$ \\
\hline 29/11/17 & $0,193 \mathrm{a}$ & $0,000 \mathrm{a}$ & $0,004 \mathrm{a}$ \\
\hline $18 / 12 / 17$ & $0,033 a$ & $0,002 \mathrm{a}$ & $0,002 \mathrm{a}$ \\
\hline \multicolumn{4}{|l|}{ Mês.ano } \\
\hline Dez 2017 & $0,214 \mathrm{a}$ & $0,000 \mathrm{a}$ & $0,013 \mathrm{a}$ \\
\hline Jan 2018 & $0,000 \mathrm{a}$ & $0,003 \mathrm{a}$ & $0,000 \mathrm{a}$ \\
\hline Fev 2018 & $0,016 \mathrm{a}$ & $0,005 a$ & $0,000 \mathrm{a}$ \\
\hline Mar 2018 & $0,017 \mathrm{a}$ & $0,000 \mathrm{a}$ & $0,000 \mathrm{a}$ \\
\hline Abr 2018 & $0,000 \mathrm{a}$ & $0,000 \mathrm{a}$ & $0,000 \mathrm{a}$ \\
\hline Mai 2018 & $0,025 \mathrm{a}$ & $0,000 \mathrm{a}$ & $0,000 \mathrm{a}$ \\
\hline Jun 2018 & $0,058 \mathrm{a}$ & $0,000 \mathrm{a}$ & $0,000 \mathrm{a}$ \\
\hline Jul 2018 & $0,055 \mathrm{a}$ & $0,000 \mathrm{a}$ & $0,011 \mathrm{a}$ \\
\hline Ago 2018 & $0,033 \mathrm{a}$ & $0,000 \mathrm{a}$ & $0,000 \mathrm{a}$ \\
\hline Set 2018 & $0,053 \mathrm{a}$ & $0,000 \mathrm{a}$ & $0,011 \mathrm{a}$ \\
\hline Out 2018 & $0,008 \mathrm{a}$ & $0,000 \mathrm{a}$ & $0,000 \mathrm{a}$ \\
\hline Nov 2018 & $0,038 \mathrm{a}$ & $0,000 \mathrm{a}$ & $0,000 \mathrm{a}$ \\
\hline Dez 2018 & $0,718 \mathrm{a}$ & $0,000 \mathrm{a}$ & $0,008 \mathrm{a}$ \\
\hline Jan 2019 & $0,071 \mathrm{a}$ & $0,007 \mathrm{a}$ & $0,007 \mathrm{a}$ \\
\hline
\end{tabular}

Ns: não significativo $(\mathrm{P}>0,05) ;$ *: $\mathrm{P}<0,05 ;$ **: $\mathrm{P}<0,01 ; * * *: \mathrm{P}<0,001$. Letras diferentes na mesma coluna indicam diferença significativa no teste de Tukey $(\mathrm{P}<0,05)$.

\section{Discussão}

A produtividade de grãos de milho não sofreu influência da população de Helicotylenchus tanto em raízes quanto no solo, além de não afetar nenhuma das variáveis produtivas avaliadas. As populações encontradas desse fitonematoide foram baixas, quando comparadas ao Pratylenchus. O 
nível populacional baixo, nessa área, pode justificar a não interferência, nas condições experimentais avaliadas, de danos na produtividade (Ferraz, 1980). Helicotylenchus não causa danos muito expressivos em culturas anuais, geralmente estão presentes em todos os tipos de solo (Tomazini et al., 2008). O Helicotylenchus está associado com as perdas nos cultivos de milho e soja, no Brasil e com altas ocorrências e incidências em amostragens nessas áreas de cultivo, porém, os danos não foram quantificados (Machado, 2014).

Criconemella não influenciou diretamente a produção de milho nem suas variáveis produtivas. Não há muitos estudos que mostram efeitos de prejuízos econômicos para esta cultura, mas se observou que houve aumento de população de Criconemella em 30 vezes sobre a população inicial quando a temperatura ficou próxima de $26^{\circ} \mathrm{C}$ (Lownsbery, 1961). Entretanto, este fitonematoide na raiz afetou negativamente a matéria seca total de capim; portanto, maior população de Criconemella na raiz de capim proporcionou menor produção de matéria seca e, consequentemente, maior proporção de guandu no total do consórcio triplo. A população de Criconemella no solo também afetou significativamente a matéria seca do capim e do guandu, a proporção de guandu na matéria seca total $e$ a população de guandu.

Os dados referentes ao Pratylenchus não foram significativos para a produção de milho, assim como nenhum dos índices fitotécnicos avaliados na cultura. Entretanto, a população de Pratylenchus na raiz afetou negativamente a população de plantas e a produção de matéria seca de guandu. Desta maneira, foi observada diminuição da proporção de matéria seca de guandu em relação à matéria seca total, que foi quantificada na área (Figura 5).

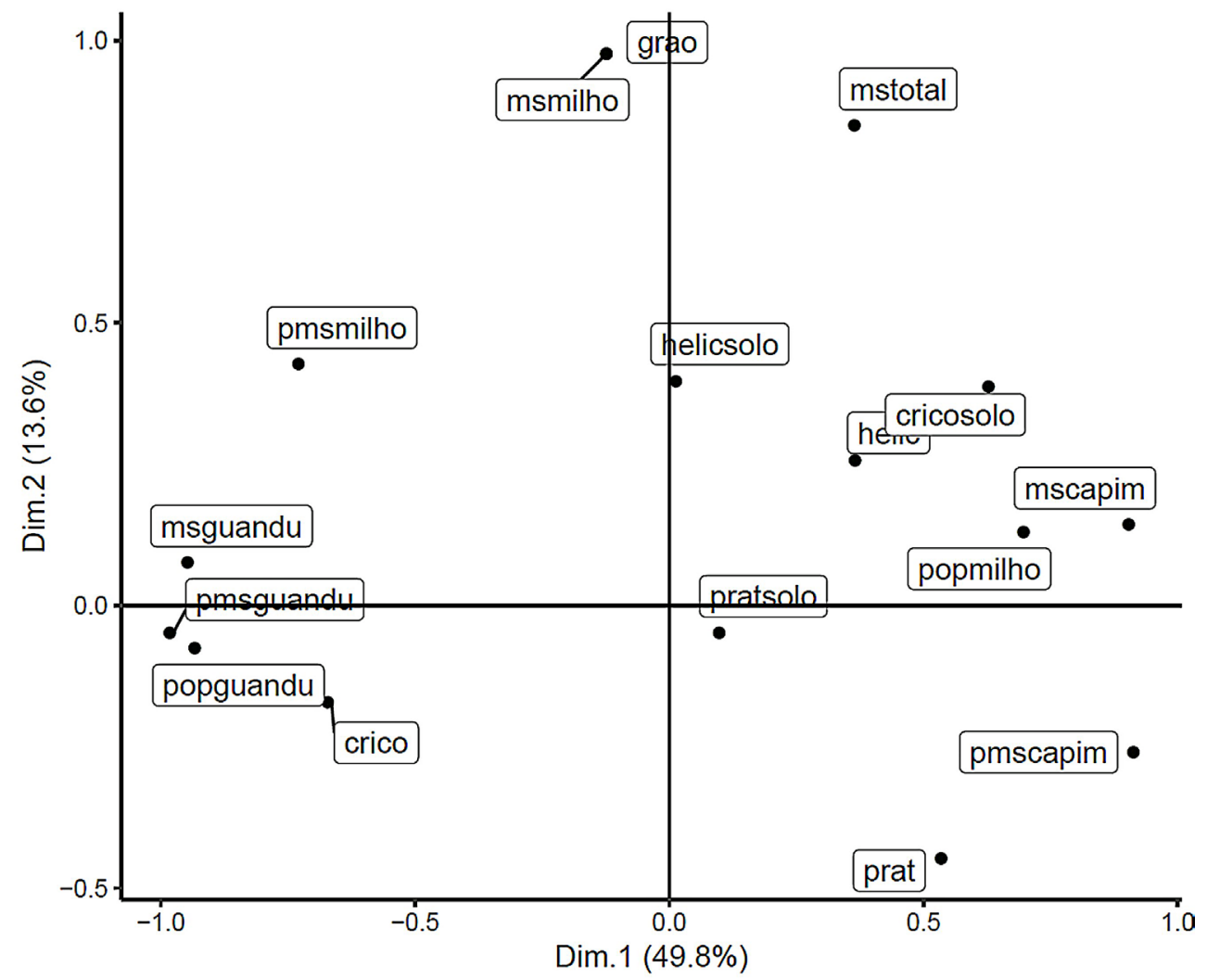

Figura 5 - Duas primeiras dimensões do resultado da análise de componentes principais das variáveis de nematoide, população e produtividade das culturas. Popguandu: população de guandu; Crico: Criconemella na raiz; Pmsguandu: proporção de guandu; Msguandu: matéria seca de guandu; Pmsmilho: proporção de matéria seca de milho; Msmilho: matéria seca de milho; Grão: grão de milho; Mstotal: matéria seca total; Helicosolo: Helicotylenchus no solo; Helico: Helicotylenchus na raiz; Cricosolo: Criconemella no solo; Mscapim: Matéria seca de capim; Popmilho: População de milho; Pratsolo: Pratylenchus no solo; Prat: Pratylenchus na raiz; Pmscapim: Proporção de matéria seca de capim. 
O consórcio triplo no SIPA pode beneficiar positivamente a cultura do milho, assim não foi observada queda na produção do milho, mesmo sendo uma cultura hospedeira favorável e multiplicadora de Pratylenchus (Debiase et al., 2016). Porém, o que se observa é que o Pratylenchus, o Helicotylenchus e o Criconemella foram encontrados mais nas raízes das plantas do sistema e menos no solo. Para a implantação do SIPA são utilizadas várias espécies de plantas que, por sua vez, são consideradas favoráveis ao parasitismo pelos fitonematoides, assim há grande multiplicação de sua população.

O gênero Helicotylenchus foi encontrado em uma parcela das amostras. Em alta infestação desse fitonematoides, espera-se que haja redução de produtividade, da mesma maneira já relatada com o Pratylenchus. Ambos penetram nas raízes das plantas parasitadas causando lesões e perdas que são de grande potencial econômico para todos os sistemas de produção encontrados no Brasil (Machado et al., 2019).

Tabela 4 - Resultados das amostragens de solo referenciando a matéria orgânica (MO) em gramas $/ \mathrm{cm}^{3}$ na área do experimento, realizadas em 2017, 2018 e 2019.

\begin{tabular}{|c|c|c|}
\hline & \multicolumn{2}{|c|}{ Teor de matéria orgânica (g/kg) } \\
\hline Junho de 2017 & Agosto de 2018 & Fevereiro de 2019 \\
\hline 12,00 & 12,00 & 20,00 \\
\hline
\end{tabular}

No consórcio triplo (milho, guandu e tamani), o milho pode ser a cultura mais beneficiada, porque os fitonematoides podem parasitar também as culturas, diminuindo a perda de produtividade pelo ataque de Pratylenchus. Desta maneira, pode ocorrer redução nas perdas econômicas da cultura. No Brasil, perdas na cultura do milho pelo ataque de Pratylenchus podem chegar a $20 \%$ de queda na produção total da cultura (Inomoto et al., 2011). Os ataques de fitonematoides estão entre os fatores que reduzem a produtividade drasticamente, além de se poder limitar a utilização de uma área de plantio. Essa severidade do dano, aliada à incidência do nematoide, depende de sua dinâmica populacional e época do ano. Ainda, estes podem ser responsáveis por perdas que podem chegar a $90 \%$ no milho e soja, quando ocorrem essas condições favoráveis para o desenvolvimento do nematoide (Godoy et al., 2014).

As populações de fitonematoides quantificadas na área não afetaram significativamente a produção de grãos de milho. A produção de biomassa dos demais componentes do consórcio (guandu e capim) foram mais evidentes para a população de alguns fitonematoides. $\mathrm{O}$ aumento da população de Criconemella na raiz do capim proporcionou menor produção de biomassa. Em gramíneas, as ausências de técnicas de manejo para o controle de nematoides propiciaram crescimento da população de Criconemella, Rosa et al. (2004), corroborando com os resultados obtidos. Por outro lado, com o aumento deste fitonematoide no solo, a matéria seca do capim teve tendência de aumento. Po de se obervar que a incidência de Criconemella, na raiz, prejudica diretamente o desenvolvimento do capim. Em contrapartida, a população no solo não pode ser considerada um bom indicativo do efeito, deste nematoide, sobre a planta forrageira. A população de Criconemella teve regressão negativa com a proporção de matéria seca de capim na matéria seca total. A proporção de guandu na matéria seca total aumentou com maior população de Criconemella na raiz. É possível que Criconemella na raiz afetem diretamente o capim, prejudicando o seu desenvolvimento e beneficiando indiretamente o guandu na competição que ocorre no consórcio triplo, e aumentando sua proporção na matéria seca total.

A matéria seca do guandu teve leve queda de acordo com o aumento do Criconemella no solo e de Pratylenchus na raiz. Da mesma forma, ambos os fitonematoides afetaram a população de guandu negativamente. Em consequência, a presença de Criconemella no solo está relacionada com a redução da proporção de guandu na matéria seca total do consórcio triplo. No entanto, vários estudos vêm mostrando que o feijão guandu tem 
reagido de diferentes maneiras aos fitonematoides (Santana et al., 2012). A relação do guandu e do capim é diretamente proporcional, quando diminui a matéria seca de um componente aumenta a do outro. Por outro lado, os resultados demonstram a possibilidade de quanto maior a população de guandu menor será a população de Pratylenchus, talvez motivado pelo efeito antagônico.

A primeira dimensão da análise de componentes principais (PCA) utilizando os dados de população de nematoides de variáveis produtivas do consórcio triplo explicou 49,8\% da variação dos dados (Figura 5). Esse componente demonstrou que a proporção de milho na matéria seca total está no mesmo grupo de variáveis relacionadas ao guandu (matéria seca, população e proporção de guandu na matéria seca total) associada à população de Criconemella na raiz e à proporção de milho na matéria seca total. Em posição oposta, observou-se um conjunto de variáveis relacionadas à produção do capim (matéria seca e proporção na matéria seca total), à população de milho e população de Criconemella no solo e de Pratylenchus e Helicotylenchus na raiz. Isso demonstrou que esses dois conjuntos de variáveis se relacionaram de maneira inversamente proporcional: quando um conjunto aumentou, o outro diminuiu. Por exemplo, Criconemella na raiz afetou negativamente a produção do capim, conforme também observado nas análises de regressão e correlação, e, consequentemente, a produção de matéria seca de guandu aumentou pela menor competição do capim no local.

No caso da população de Pratylenchus na raiz, observou-se efeito negativo sobre a produção e população de guandu, que também foi identificado nas análises de regressão $e$ correlação. Por consequência, maior população desse fitonematoide está relacionada com maior produção de matéria seca de capim, devido à menor competição do guandu com o capim no local.

$\mathrm{Na}$ análise da segunda dimensão da PCA (Figura 5), observou-se a população de Pratylenchus em um extremo, e a produção de grãos de milho, matéria seca de milho e matéria seca total em outro extremo. Esse resultado sugeriu uma relação negativa entre a população de Pratylenchus e produção do milho, indicando efeito negativo do fitonematoide sobre a cultura. No entanto, esse efeito não foi observado nas análises de regressão e correlação. A análise em conjunto dos dois componentes da PCA demonstrou que a produção do milho (tanto grãos quanto matéria seca) não foi afetada pela população e produção do capim e do guandu, indicando que o milho não está sendo prejudicado pela competição com as outras espécies incluídas no consórcio.

Observou-se que o consórcio triplo, além de beneficiar a cultura do milho - que foi o foco do trabalho -, tendenciou a também beneficiar o solo, pois aumenta automaticamente o controle biológico dos fitonematoides, pelo aumento dos microrganismos antagônicos. Desta forma, deixa o solo em equilíbrio, sendo a mineralização da matéria orgânica a parte que mais contribui para este fim.

A primeira dimensão indicou forte competição entre capim e guandu (quando um aumenta, o outro diminui e vice-versa). Ainda, analisando todos os resultados em conjunto, observou-se que o Pratylenchus prejudicou o desenvolvimento do guandu, e o Criconemella prejudica o capim; entretanto, o milho não foi influenciado por esses fitonematoides. A cultura do milho, mesmo sendo hospedeira favorável ao Pratylenchus, não demostrou diferença em sua produtividade (Inomoto, 2011).

Observaram-se relações significativas entre a população de Pratylenchus na raiz e a temperatura ambiente (média, mínima e máxima), bem como entre Pratylenchus no solo e a precipitação acumulada (Figura 6). Quanto maior a precipitação acumulada, maior a população do Pratylenchus. A umidade está relacionada diretamente com a viabilidade do fitonematoides do gênero Pratylenchus. McDonald \& Berg (1993), que avaliaram diferentes regimes de irrigação sobre as injúrias de $P$. zeae e $P$. brachyurus na cultura do milho, mencionaram que o aumento populacional de fitonematoides estava diretamente ligado ao aumento de umidade no solo.

A grande maioria dos fitonematoides tem como faixa de temperatura ideal para sua reprodução entre 15 e $30^{\circ} \mathrm{C}$. Eles podem tornarse inativos e/ou levarem à morte pelo tempo de exposição com temperatura baixa, que varia entre 5 a $15^{\circ} \mathrm{C}$ e/ou temperatura muito alta próxima de $40^{\circ} \mathrm{C}$ (Freitas, 2014). Observouse isso quando a variação entre a temperatura mínima e a temperatura máxima varia entre 15 a $30^{\circ}$. Percebeu-se que a variação está diretamente ligada ao aumento da população de Pratylenchus 
por causa do ambiente climatológico favorável à reprodução desse fitonematoides (Freitas et al., 2014). Quando analisada a relação de temperatura máxima, observa-se um modelo significativo não somente para Pratylenchus, mas também o Criconemella, ambos na raiz, pois eles são diretamente proporcionais. Por outro lado, nos meses de temperaturas mínimas baixas verifica-se que a população se mantem em equilibrio e até em leve diminuição. Ainda foi observado que a umidade relativa não influencia significativamente na dinâmica populacional do Pratylenchus, assim como também não influenciou no Criconemella; entretanto, teve leve influência no Helicotylenchus. Desta forma, seriam necessárias novas avaliações, ao passar dos anos, para verificar tal significância.

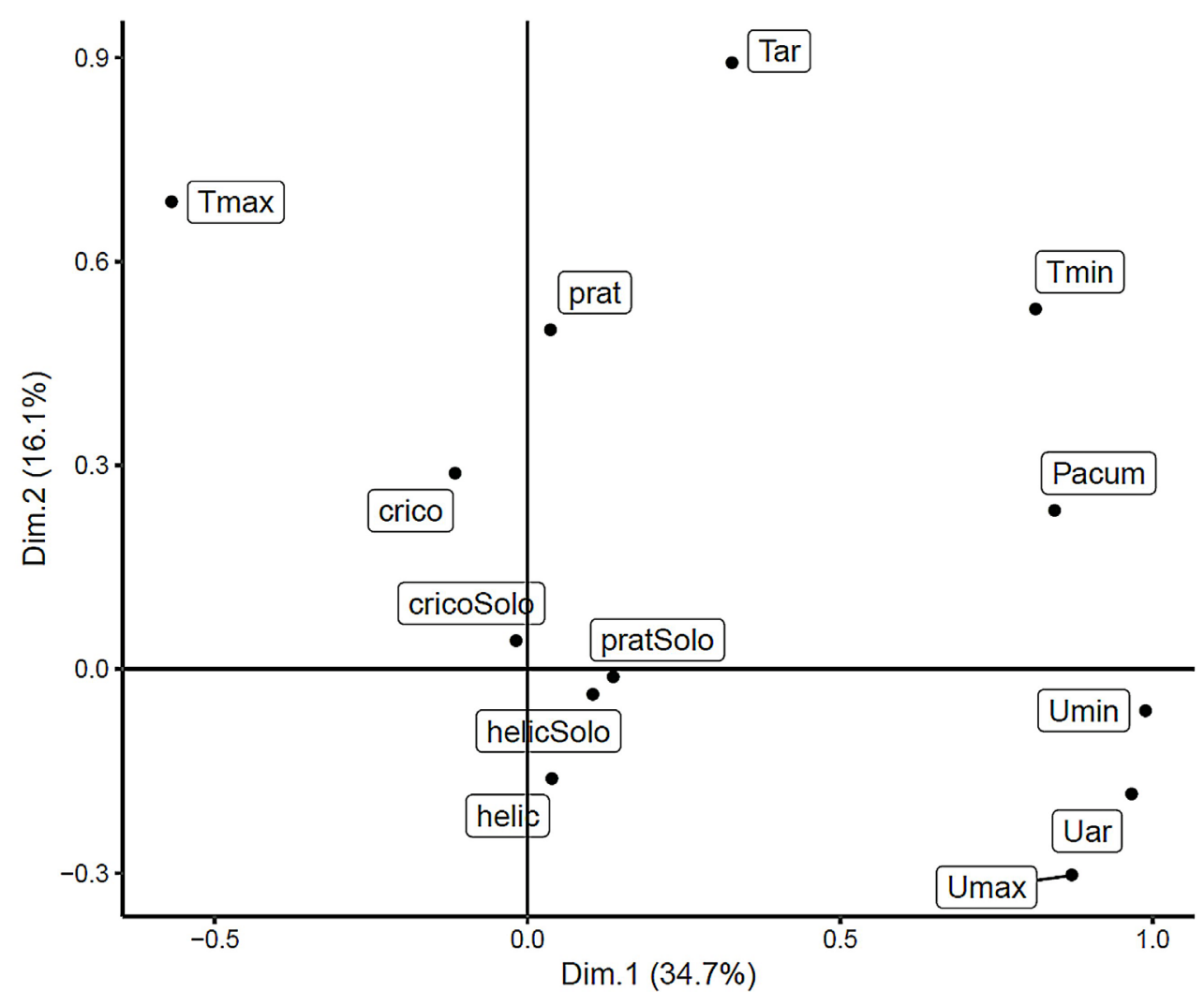

Figura 6 - Análise de componentes principais de população de nematoide e variáveis meteorológicas. Tmax: Temperatura máxima; Crico: Criconemella na raiz; Cricosolo: Criconemella no solo; Tar: Temperatura do ar; Prat: Pratylenchus na Raiz; Tmin: Temperatura mínima; Pacum: Precipitação acumulada; Pratsolo: Pratylenchus no solo; Helicosolo: Helicotylenchus no solo; Helico: Helicotylenchus na Raiz; Umin: Umidade mínima; Uar: Umidade do ar: Umax: Umidade máxima.

\section{Conclusão}

As épocas de semeio não interferiram nas populações de fitonematoides, nas condições experimentais avaliadas. As populações de Criconemella e de Helicotylenchus não sofreram influência em sua população, nem pelas épocas de coleta e nem devido às épocas de semeio. Pratylenchus foi influenciado pela época de coleta, tendo relação com o índice de precipitação acumulada.

\section{Agradecimentos}

Agradecemos ao Instituto Federal Goiano, Campus Iporá; ao Programa de Mestrado Profissional em Bioenergia e Grãos (PPGBG), do Instituto Federal Goiano, Campus Rio Verde; $e$ ao produtor e sua família, proprietários do sítio "Boa Esperança", pelo apoio na realização deste trabalho. 


\section{Referências}

Alves TCU, Da Silva RA, Borges DC, Motta LCC \& Kobayasti L. Reação de cultivares de soja ao nematóide das lesões radiculares Pratylenchus brachyurus. Revista Biodiversidade, 10(1): 73-79, 2011.

Asmus GL \& Ishimi CM. Flutuação populacional de Rotylenchulus reniformis em solo cultivado com algodoeiro. Pesquisa Agropecuária Brasileira, Brasília, 44(1): 51-57, 2009.

Balbino LC, Barcellos AO \& Stone LF. 2011. Marco referencial: integração lavoura-pecuária-floresta. Embrapa. Brasilia. 130p.

Bates D, Maechler M \& Bolker B. Ime4. 2011: Linear mixed-effects models using $\mathrm{S} 4$ classes.

Chiamolera FM, Dias-Arieira CR, Souto ER, Biela F, Cunha TPL, Santana SM \& Puerari HH. Suscetibilidade de culturas de inverno a Pratylenchus brachyurus e atividade sobre a população donematóide na cultura do milho. Nematropica, 42: 267-275, 2012.

Cobucci T, Wruch FJ \& Kluthcouski J. Opções de integração lavoura-pecuária e alguns de seus aspectos econômicos. Informe Agropecuário, 28(240): 25-42, 2007.

Debiasi H, Franchini JC, Dias WP, Ramos Junior EUR \& Balbino Junior AB. Práticas culturais na entressafra da soja para o controle de Pratylenchus brachyurus. Pesquisa agropecuária brasileira, Brasília, 51(10): 1720-1728, 2016.

Dong Z, Hou R, Chen Q, Ouyang Z \& Ge F. Response of soil nematodes to elevated temperature in conventional and no tillage cropland systems. Plant and Soil: An International Journal on Plan-Soil Relationships, 373: 907-918, 2013.

Coolen WA \& D'Herde CJ. 1972. A method for the quantitative extraction of nematodes from plant tissue. Ghent, State Nematology and Entomology Research Station. 77p.

Ferraz S. Reconhecimento das espécies de fitonematoides presentes nos solos do estado de Minas Gerais. Experientia (Brasil), 26(11): 255-328, 1980.

Ferraz LCCB. O nematoide Pratylenchus brachyurus e a soja sob plantio direto. Revista Plantio Direto, Passo Fundo, 96: 23-32, 2006.

Freitas LG, Oliveira RDA de L \& Ferraz S. 2014. Introdução a Nematologia. Departamento de Fitopatologia. Universidade Federal de Viçosa. Viçosa. Minas Gerais. 92p.

Godoy CV et al. Eficiência de fungicidas para o controle da ferrugemasiática da soja, Phakopsora pachyrhizi, na safra 2013/14: resultados sumarizados dos ensaios cooperativos. Embrapa Soja: Londrina, 103: 1-7, 2014.

Hugot JP, Baujard P \& Morand S. Biodiversity in helminths and nematodes as a field of study: an overview. Nematology, 3: 199-208, 2001.

Inomoto MM. Avaliação de resistência de 12 hibridos de milho a Pratylenchus brachyurus. Tropical Plant Pathology, 36: 308-312, 2011.

Inomoto MM, Siqueira KMS \& Machado ACZ. Sucessão de cultura sob pivô central para controle de fitonematoides: variação populacional, patogenicidade e estimativa de perdas. Tropical Plant Pathology, 36: 178-185, 2011.

Inomoto MM \&, Asmus GL. 2013. Manejo de nematoides em sistemas consorciados. Estabilidade e produtividade, Dourados-MS, p. 1-8. In: Seminário nacional de milho safrinha, Embrapa Dourados: Embrapa Agropecuária Oeste. 8p.

Jenkins WR. A rapid centrifugal-flotation technique for separating nematodes from soil. Plant Disease Reporter, 48(9): 692, 1964.

Lownsbery BF. Factors affecting population levels of Criconemoides xenoplax. Phytopathology, 51: 101103, 1961.

Machado ACZ. Ameaças atuais dos nematóides à agricultura brasileira. Agricultural Science and Technology, 20: 26-35, 2014.

Machado ACZ, Amaro PM \& Silva SAD. Two novel potential pathogens for soybean. PLoS One, 14(8), 2019.

Mattos JKA, Huang SP \& Pimentel CMRM. Grupos tróficos da comunidade de nematoides do solo em oito sistemas de uso da terra nos cerrados do Brasil central. Revista Brasileira de ciências do solo, 30: 267273, 2006.

Mc Donald AH \& Berg VD. Effect of watering regimen on injury to corn and grain sorghum by Pratylenchus species. Jounal of Nematology, Hanover, 25(4): 654658, 1993.

Moreira F. 2012. Manual de biologia do solo tropical. Instituto Nacional de Ecologia, 376p.

Rosa RCT, Moura RM \& Pedrosa EMR. Efeitos do uso de Crotalaria juncea e Carbofuran em fitonematoides ectoparasitos de cana-de-açúcar, Brasilia. Fitopatologia brasileira, 29(4): 447-449, 2004.

Santana SM, Dias-Arieira CR, Biela F, Cunha TPL, Chiamolera FM, Roldi M \& Abe VHF. Plantas antagônicas no manejo de Meloidogyne incognita, em solo arenoso de área de cultivo de olerícolas. Nematropica, 42: 287-294, 2012. 
Tomazini MD, Ferraz LCCB \& Monteiro AR. Abundância e diversidade de nematoides em áreas contíguas de vegetação natural e submetidas a diferentes tipos de uso agrícola. Nematologia Brasileira, 32(3): 185-193, 2008.

Vilela L, Martha Junior GB, Marchão RL, Guimarães Junior R, Barioni LG \& Barcellos AO. 2008. Integração Lavoura-Pecuária. p. 931-962. In: Faleiro FG \& Farias
Neto AL Eds. Savanas: desafios e estratégias para o equilíbrio entre sociedade, agronegócio e recursos naturais. Planaltina: Embrapa Cerrados; Brasília: Embrapa Informação Tecnológica.

Yorinori JT, Charchar MJD \& Nasser LCB. 1993. Doenças da soja e seu controle, p. 333-390. In: Cultura da Soja nos Cerrados. Piracicaba.

\section{Biodiversidade Brasileira - BioBrasil. \\ Fluxo Contínuo}

n. 1,2021

http://www.icmbio.gov.br/revistaeletronica/index.php/BioBR

Biodiversidade Brasileira é uma publicação eletrônica científica do Instituto Chico Mendes de

Conservação da Biodiversidade (ICMBio) que tem como objetivo fomentar a discussão e a disseminação de experiências em conservação e manejo, com foco em unidades de conservação e espécies ameaçadas.

ISSN: 2236-2886 